\title{
Bullous varicella in a preschool-aged patient
}

\author{
Halyna Pavlyshyn, Ivanna Horishna \\ Department of Pediatrics, Ivan Horbachevsky Ternopil National Medical University, Ternopil, Ukraine
}

\begin{abstract}
Varicella (chickenpox) is a highly contagious febrile rash illness caused by primary infection with Varicella zoster virus (VZV/HHV-3), which is one of the eight human herpes viruses, transmitted by respiratory contact with aerosolised respiratory secretions and blister secretions or by direct contact with them. The typical course of varicella in immunocompetent unvaccinated children is generally mild and uncomplicated. A clinical case of atypical bullous varicella in a preschool child, who was thought to be immunocompetent, was consequently analysed. The disease had typical moderate course, aggravated with characteristic skin syndrome. Hospitalisation and adequate, timely treatment of the patient according to modern guidelines led to his fast, complete recovery and showed the effectiveness of such therapy.
\end{abstract}

\section{KEY WORDS:}

complications, children, varicella, bullous varicella.

\section{INTRODUCTION}

Varicella (chickenpox) is a highly contagious febrile rash illness caused by primary infection with Varicella zoster virus (VZV/HHV-3), which is one of the eight human herpes viruses, transmitted by respiratory contact with aerosolised respiratory secretions and blister secretions or by direct contact with them [1].

The world annual incidence of varicella is estimated at 80-90 million cases. Prior to the introduction of the varicella vaccine in 1995, there were 4 million cases, over 11 thousand hospitalisations, and 100-150 deaths annually in the United States, the majority of which occurred in children. Implementation of the one-dose routine varicella vaccination program in 1996 resulted in a 90\% decline in varicella incidence, and adding a second dose in 2006 resulted in an additional 85\% decline in the disease [2]. It is most commonly seen in children under the age of 10 years in countries where live attenuated varicella vaccine is not routinely administered [3]. Varicella vaccine is not included to the immunisation calendar of Ukraine as a planned obvious vaccination of healthy children, although 120-150 thousand cases of varicella are registered annually in the country $[4,5]$.

\section{CASE REPORT}

The typical course of varicella in immunocompetent unvaccinated children is generally mild and uncomplicated. We present a case of an atypical bullous varicella from our practice.

A boy of 5 years 10 months entered the infectious department on the fourth day of his disease. On admission he complained of big blisters, "honey" crusts on his perioral region, left ear, neck, trunk, and legs, and vesicles all over the body and on the scalp, body temperature $38.5^{\circ} \mathrm{C}$, malaise, and poor appetite.

Present history: the disease began four days earlier from maculopapular rash on the scalp and trunk, and body temperature was $38.5^{\circ} \mathrm{C}$. The next day, a new rash

\section{ADDRESS FOR CORRESPONDENCE:}

Halyna Pavlyshyn, Department of Paediatrics, Ivan Horbachevsky Ternopil National Medical University, Maidan Voli 1, 46001 Ternopil, Ukraine, ORCID: 0000-0003-4106-2235, e-mail: halynapavlishin@gmail.com 
TABLE 1. Laboratory tests

\begin{tabular}{|c|c|c|c|c|c|c|c|c|c|c|}
\hline \multirow[t]{2}{*}{ Date } & \multirow{2}{*}{$\begin{array}{c}\text { RBC } \\
1012 / l\end{array}$} & \multirow{2}{*}{$\begin{array}{l}\mathrm{Hb} \\
\mathrm{g} / \mathrm{l}\end{array}$} & \multirow{2}{*}{$\begin{array}{c}\text { Platelets } \\
109 / 1\end{array}$} & \multirow{2}{*}{$\begin{array}{l}\text { WBC } \\
109 / I \\
\end{array}$} & \multirow{2}{*}{$\begin{array}{c}\text { Eos. } \\
\%\end{array}$} & \multicolumn{2}{|c|}{ Neutr. \% } & \multirow{2}{*}{$\begin{array}{c}\text { Lymph. } \\
\%\end{array}$} & \multirow{2}{*}{$\begin{array}{c}\text { Mon. } \\
\%\end{array}$} & \multirow{2}{*}{$\begin{array}{c}\text { ESR } \\
\mathrm{mm} / \mathrm{h}\end{array}$} \\
\hline & & & & & & Stab. & Segm. & & & \\
\hline 30.12 & 4.14 & 113 & 172 & 7.4 & 1 & 2 & 46 & 37 & 14 & 3 \\
\hline 4.01 & 4.18 & 125 & - & 7.3 & 1 & 2 & 34 & 56 & 7 & 4 \\
\hline
\end{tabular}

TABLE 2. Blood biochemical test

\begin{tabular}{|l|c|c|}
\hline Parameter & 30.12 & Norm \\
\hline AST, EU/I & 28 & $<40$ \\
\hline ALT, EU/I & 17 & $<37$ \\
\hline GGTP, EU/I & 23 & $7-50$ \\
\hline Amylase, EU/I & 44 & $<80$ \\
\hline Total bilirubin, $\mu \mathrm{mol} / \mathrm{I}$ & 4.1 & $<21.0$ \\
\hline Protein, g/l & 72 & $53-89$ \\
\hline Glucose, $\mathrm{mmol} / \mathrm{l}$ & 4.1 & $4.20-6.10$ \\
\hline Creatinine, $\mu \mathrm{mol} / \mathrm{I}$ & 39.9 & $26.5-97.0$ \\
\hline Urea, mmol/I & 2.92 & $1.70-8.30$ \\
\hline Alkaline phosphatase, EU/l & 159 & $42-378$ \\
\hline
\end{tabular}

appeared on the head, trunk, and extremities, previous elements changed to vesicles, and body temperature grew up to $39.2^{\circ} \mathrm{C}$. The boy was treated symptomatically (antipyretics, local antiseptics). A few erythematous macules 3-4 cm in diameter appeared on his shins and the left ear on the third day and changed to bullae in a few hours; body temperature was febrile. Massive similar erythema appeared on his thighs, neck, trunk, and near the mouth during the subsequent night, although he was hospitalised on the fourth day of the disease.

Past history was unremarkable. The boy was not immunised with varicella vaccine. He had contacted an ill sister who started typical varicella 16 days before him. On admission the patient's general condition was mod- erately grave because of toxic and skin syndromes. He was conscious, lying on his back, with partly flexed hips and knees. Vital signs: HR 126, RR 22 per minute, $\mathrm{SpO}_{2}$ $97 \%$. Vesicular rash $0.2-0.3 \mathrm{~cm}$ with cloudy content was seen all over the body, predominantly on legs. Bullous flat, sometimes confluent, partly eroded or centrally crusted rash 3-5 $\mathrm{cm}$ was present predominantly on his thigs, shins, trunk, neck, and left ear; large "honey" crusts periorally, on the forehead; and small crusts on the scalp and face (Fig. 1).

Visible mucosa was pinkish with two erosions on the soft palate. Anterior and posterior cervical, suboccipital, submandibular lymphatic nodes up to $0.8 \mathrm{~cm}$ in diameter were painless, elastic, and movable on palpation. Meningeal symptoms were negative. Breathing was vesicular, and heart tones were loud and rhythmic. Abdomen was soft and painless, with mild hepatosplenomegaly ( +2 and $+1 \mathrm{~cm}$ correspondingly) on palpation. Urination was regular, but constipation was present for three days. In laboratory tests, CBC showed monocytosis on admission and mild lymphocytosis at discharge (Table 1). Blood biochemical test was within the reference range (Table 2).

Immune-enzyme test done on the fourth day of exanthema showed specific varicella-zoster (VZV) antibodies: IgM - 3.22 IU (positive) and IgG - 0.48 IU (negative). Bacterial culture of the bulla's exudate on admission was negative. Basic immunological tests were not performed. Hence, atypical bullous varicella was diagnosed.

The patient was treated according to national Ukrainian guidelines [6]. Aetiological therapy included oral acyclo-
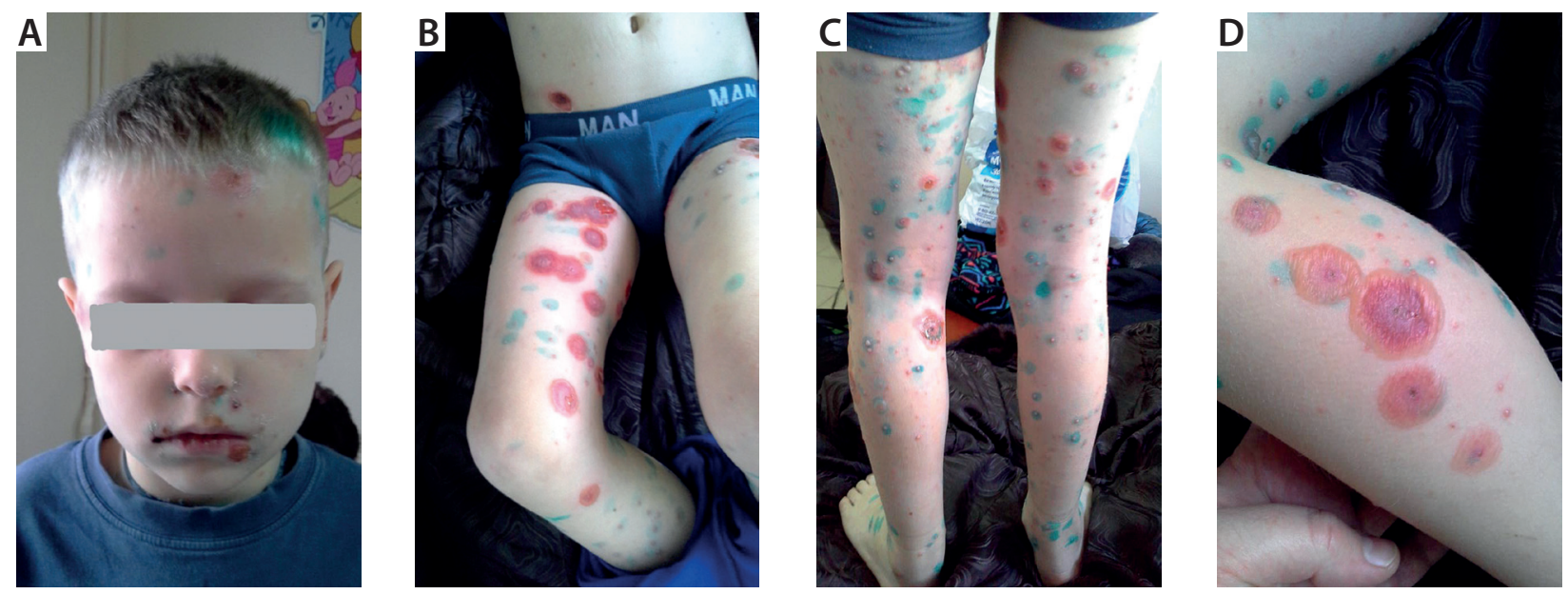

FIGURE 1. Bullous varicella: A) crusted lesions on the face on the day of admission ( $4^{\text {th }}$ day of the disease); B) bullous lesions on the right thigh on the day of admission ( $4^{\text {th }}$ day of the disease); C, D) bullae and vesicles on the legs on the day of admission ( $4^{\text {th }}$ day of the disease) 

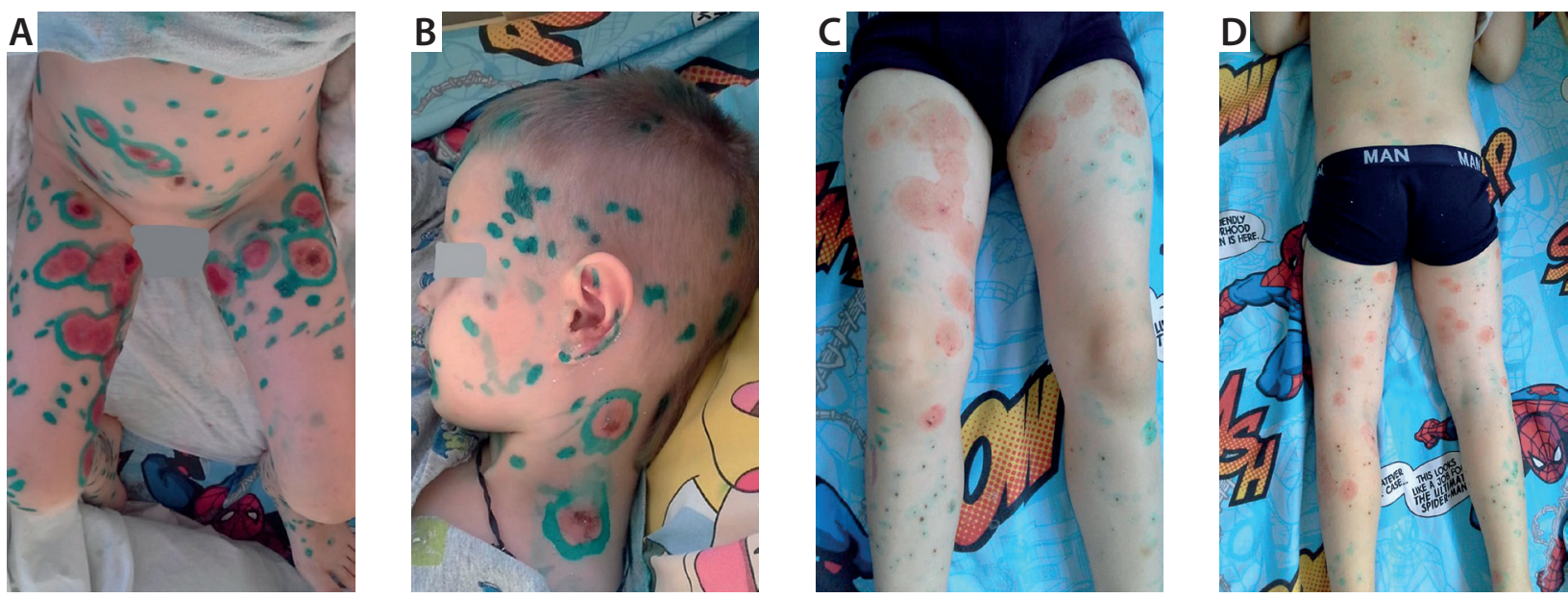

FIGURE 2. Bullous varicella: A, B) confluent and dried lesions on the $2^{\text {nd }}$ day of treatment ( th $^{\text {th }}$ day of the disease); C, D) epithelised lesions with pigmentation on the $12^{\text {th }}$ day of the disease

vir $400 \mathrm{mg}(20 \mathrm{mg} / \mathrm{kg}) 4$ t.d. for seven days; pathogenetic therapy with polyvalent intravenous immunoglobulin (IVIG) $100 \mathrm{ml}$ of $10 \%$ solution $(0.5 \mathrm{~g} / \mathrm{kg})$ for three days, and intravenous detoxication $(200 \mathrm{ml}$ of $0.9 \% \mathrm{NaCl}$ solution and $200 \mathrm{ml}$ of $5 \%$ glucose solution twice a day) for three days; symptomatic therapy was given with antipyretics and antihistamines to decrease itching, as well as local antiseptics. Cefazolin in average doses was given for seven days intravenously empirically to prevent bacterial contamination of erosions, in spite of negative bacterial culture obtained later.

In dynamics, the patient's body temperature normalised until the next evening, and there were no new lesions; bullous lesions increased in diameter up to 4-6 cm on the fifth day of illness (second day in the hospital) and started healing without new erosions (Fig. 2A and $2 \mathrm{~B}$ ). Oral erosions healed within four days and bullae epithelised completely with slight pigmentation in eight days of admission (12th day of illness) (Fig. 2C and 2D). Therefore, the patient was successfully discharged.

In follow-up, the boy was examined one year later: he was generally healthy, the skin in the location of previous lesions had normal colour and structure without pigmentation or scarring, and no late complications developed for this period.

\section{DISCUSSION}

The typical course of varicella in immunocompetent unvaccinated children is generally mild with pruritic rash that progress within 24-48 hours from macules to papules and vesicles on an erythematous base with clear fluid before crusting. The rash primarily appears on the scalp, crops 2-4 times in 4-6 days with trunk and extremities involvement, but has centripetal distribution. Lesions then crust over and fall off in the next $1-2$ weeks. Lesions also can occur on mucous membranes of the oropharynx, respiratory tract, genitals, and conjunctiva. Lesions seen on the third to fifth day of the disease are usually 1-4 mm in diameter and pleomorphic. 200-500 are usually seen in typical moderate varicella. The rash is accompanied with malaise and moderate fever for 2-3 days. The illness usually lasts about a week [2].

Varicella has atypical course in vaccinated persons known as "breakthrough varicella" due to infection with wild type VZV, which occurs more than 42 days after varicella vaccination. It is characterised with less than 50 lesions of maculo-papular character with no or few vesicles, low-grade fever, and short duration. It is less contagious than primary varicella. However, the clinical features typical for varicella can develop in $25-30 \%$ of vaccinated persons as in unvaccinated $[1,3]$. Congenital varicella and neonatal varicella also belong to atypical clinical forms $[2,7]$.

The diagnosis of VZV infection is usually made clinically by the appearance of the typical skin rash. In confusing or unusual cases, the diagnosis may be made by identifying VZV DNA in skin lesions by PCR or specific IgM measurement [1].

Varicella in the healthy immunocompetent host is usually a mild self-limited disease, but complications can occur. Groups at increased risk for severe atypical disease course and complications include neonates and infants, adolescents, adults, and immunocompromised patients. Complications such as bacterial skin superinfections, pneumonia, bronchitis, laryngotracheitis, and gastrointestinal tract disorders are the most characteristic in children under two years of age. Cerebellar ataxia, encephalitis, aseptic meningitis, transverse myelitis, and Guillain-Barre syndrome are the main viral CNS complications, they are more frequent in children 3-6 years of age $[8,9]$. Peripheral facial palsy, described by Hanalioğlu et al. [10], is an extremely rare neurologic complication of varicella. One more extremely rare neurologic complication (Vernet syndrome, a unilateral palsy of glossopharyngeal, vagus, and accessory nerves) was presented by 
Ferreira et al. [11]. Other viral complications include glomerulonephritis, myocarditis, arthritis, orchitis, uveitis, iritis, acute retinal necrosis, mild hepatitis, and pancreatitis. Reye syndrome as an unusual complication of varicella occurs almost exclusively in children who take aspirin during the acute illness. Haematological disorders include mild neutropaenia and thrombocytopaenia, rare purpura fulminans, disseminated intravascular coagulation, and Henoch-Schönlein purpura, which could be clinically presented as "varicella haemorrhagica" [2, 12-15]. Acute liver failure (ALF) and hemophagocytic lymphohistiocytosis (HLH) are extremely rare complications induced by VZV infection [16].

Secondary bacterial infection of skin lesions, usually due to Staphylococcus aureus or Streptococcus pyogenes, and secondary bacterial pneumonia dominate among other bacterial complications [2, 7]. Staphylococcal or streptococcal toxic shock syndrome, osteomyelitis, necrotising fasciitis (previously known as "varicella gangrenosa", caused by exotoxin of group A $\beta$-haemolytic streptococci, which lead to an extensive local tissue destruction) belong to the group of more serious bacterial complications $[13,17,18]$. Casuistical varicella complication by calvaria osteomyelitis was described by Sommer et al. [19].

Bullous chickenpox, also known as varicella bullosa, is a rarely reported variant of chickenpox (occurring in $0.5 \%$ of cases) that can affect both children and adults. It can occur both in previously healthy persons and in immunocompromised ones [20,21].

In the first case, varicella bullosa resembles ordinary primary varicella but is complicated by the formation of giant flat bullae $2-3 \mathrm{~cm}$ or more in diameter with cloudy serous, seropurulent, or serosanguinous content and the formation of large erosions, when blisters ruined. Varicella bullosa has a mainly benign course with slightly longer epidermis healing and slight pigmentation - up to two weeks usually. Despite bullous skin lesions, mucosa changes may be absent or small and not numerous. General symptoms are usually mild to moderate [22-25]. Such a course of the disease, with moderate general symptoms, was seen also in our patient. Initially, it had a typical beginning, as in varicella in unvaccinated immunocompetent persons; bullous elements appeared on the third day of the disease and progressed without specific treatment. In spite of massive confluent skin lesions there were few small lesions on oral mucosa only. Due to the combination of specific antiviral medicine, adequate doses of polyvalent intravenous immunoglobulin, and systemic and local antibacterial treatment, the patient's disease resolved completely through healing of all bullous lesions with slight pigmentation up to the $12^{\text {th }}$ day of his illness.

If varicella bullosa occurs in an immunocompromised person, it usually has a severe relapsed course with large elements, poor prolonged healing for more than three weeks, and secondary complications $[26,27]$.
Despite the fact that toxigenic Staphylococcus aureus is considered to play the main role in the aetiology of varicella bullosa [26, 27], in some patients, vesicles cultures were negative $[24,25]$. Bacterial culture taken from the patient's bullae before initiation of antibacterial therapy was also negative. The pathogenesis of bullae remains unclear; it is either a distinct manifestation of VZV or the result of coinfection with exfoliative toxin-producing Staphylococcus species. Bullae may represent coalescence of multiple vesicles or result from superimposed bullous impetigo/staphylococcal scalded skin syndrome [28]. The histopathology is distinct from bullous impetigo and comprises intraepidermal bullae with multinucleated keratinocytes (giant cells) and intranuclear inclusions demonstrated by Tzank smear, which is characteristic for varicella $[24,26]$. Modern techniques including polymerase chain reaction strongly support varicella zoster virus involvement in the development of bullae [29]. The VZV aetiology of the disease in our patient was proven immunologically by measuring specific IgM antibodies without histopathological examination.

Routine treatment of varicella in healthy children is not uniformly recommended, although an oral form of the acyclovir is available for children 2-12 years of age in typical uncomplicated severe cases, and for adolescents in moderate to severe cases. For the best outcome, antivirals should be given as soon as possible to immunocompromised individuals and to anyone who seems to be developing severe varicella [1]. However, treatment of varicella bullosa includes average recommended doses of acyclovir for 1-2 weeks depending disease severity and antistaphylococcal antibiotics for 10-14 days together with adequate supportive care. Adjunctive therapy with intravenous immunoglobulin may also be beneficial in patients with streptococcal cutaneous complications. The prognosis of this form of chickenpox is usually excellent [25]. In the presented case the patient was treated successfully with complete recovery according the national Ukrainian guidelines with an adequate dose of acyclovir, its combination with polyvalent intravenous immunoglobulin, and antibacterial and symptomatic therapy, which corresponds to modern European guidelines [30, 31].

\section{CONCLUSIONS}

Bullous varicella is a rare atypical form of varicella in immunocompetent children, which has some clinical and morphological peculiarities. Adequate, timely treatment of bullous varicella in immunocompetent children, according modern guidelines, leads to complete recovery in a short period of time. Vaccination with a live attenuated varicella vaccine is the single effective method to prevent severely complicated disease, and it is recommended for inclusion in the immunisation calendar of Ukraine for obvious vaccination of healthy children from 12 months of age. 


\section{DISCLOSURE}

The authors declare no conflict of interest.

\section{REFERENCES}

1. Gershon A, Takahashi M, Seward JF. Live attenuated varicella vaccine. In: Vaccines, $6^{\text {th }}$ ed., Plotkin S, Orenstein W, Offit P (eds.). WB Saunders, Philadelphia 2013: 837-869.

2. Padlipsky P, Young KD. Varicella and Zoster. In: Life-Threatening Rashes an Illustrated, Practical Guide, Rose E. Springer 2018: 141-158.

3. Gershon AA, Breuer J, Cohen JI, et al. Varicella zoster virus infection. Nat Rev Dis Prim 2015; 1: 15016.

4. Order of the Healthcare Ministry of Ukraine No. 947 as of May 18, 2018. [On Amendments to the Immunization Calendar of Ukraine]. http://moz.gov.ua/article/ministry-mandates/nakazmoz-ukraini-vid-18052018--947-pro-vnesennja-zmin-do-kalendarja-profilaktichnih-scheplen-v-ukraini

5. Berger S. Infectious Diseases of Ukraine: 2019 ed. Gideon 2019: 311.

6. Order of the Healthcare Ministry of Ukraine No. 354 as of July 09, 2004. [On Approval of Protocols for Diagnosis and Treatment of Infectious Diseases in Children]. http://old.moz.gov.ua/ua/portal/ dn_20040709_354.html

7. Stave GM, Wald PH. Physical and Biological Hazards of the Workplace, 3rd ed. Wiley and Sons 2016: 343.

8. Smok B, Franczak J, Domagalski K, Pawłowska M. Varicella complications in children one-site Polish population - a 19-year long survey. Przegl Epidemiol 2018; 72: 459-467.

9. Al-Turab M, Chehadeh W. Varicella infection in the Middle East: Prevalence, complications, and vaccination. J Res Med Sci 2018; 23: 19.

10. Hanalioğlu D, Özsürekci Y, Büyükçam A, et al. Acute peripheral facial paralysis following varicella infection: An uncommon complication. Turk J Pediatr 2018; 60: 99-101.

11. Ferreira J, Franco A, Teodoro T, et al. Vernet syndrome resulting from varicella zoster virus infection-a very rare clinical presentation of a common viral infection. Varicella and herpes zoster: challenges for public health. J Neurovirol 2018; 24: 379-381.

12. Sterling JC. Viral infections. In: Rook's Textbook of Dermatology, $8^{\text {th }}$ ed., Burns T, Breathnach S, Cox N, Griffiths C (eds.). WileyBlack, Oxford 2010: 33.22-33.26.

13. Gnan JW Jr. Varicella-zoster Virus: Atypical Presentations and Unusual Complications. J Inf Dis 2002; 186: 91-98.

14. Dauger S, Le Goff J, Deho A, Jones P. Varicella zoster in sudden infant death. BMJ Case Rep 2018; 11: e227034.

15. Gupta R, Tyagi M, Balakrishnan D, Rani PK. Acute retinal necrosis (ARN) following chickenpox in a patient of Vogt-Koyanagi-Harada (VKH) syndrome using immunosuppressants. BMJ Case Rep 2018; 11: e227290.

16. Zhang LN, Guo W, Zhu JH, Guo Y. Successful rescue of acute liver failure and hemophagocytic lymphohistiocytosis following varicella infection: A case report and review of literature. World J Clin Cases 2018; 6: 659-665

17. Sharma A, Agarwal S, Sharma A, Kumar M. Varicella gangrenosum in adult: A fatal chickenpox complication. BMJ Case Rep 2019; 12: e226363.

18. Bianchi L, Simonetti S, Hansel K, et al. Gangrenous Chickenpox with Atypical Clinical and Histopathological Findings. Dermatopathology (Basel) 2018; 5: 38-40.

19. Sommer T, Karsy M, Driscoll MJ, Jensen RL. Varicella-Zoster Virus Infection and Osteomyelitis of the Skull. World Neurosurg 2018; 115: 297-300.
20. Haimi M, Ben-Arush MW, Kassis I, et al. Bullous herpes zoster in a child with leukemia: case report and review of the literature. J Pediatr Hematol Oncol 2004; 26: 587-590.

21. Tsai MJ, Kuo HT, Chen HC. The clinical picture: multiple huge bullae after renal transplant. Cleveland Clin J Med 2009; 76: 221.

22. Yoshida M, Kusuda S, Tezuka T. Varicella bullosa in an adult. Br J Dermatol 1990; 123: 846-848.

23. White GM, Broska P. Vesicles and bulla in an infant. Bullous varicella (chicken pox complicated by bullous impetigo). Arch Dermatol 1994; 130: 107, 110.

24. Beniwal R, Gupta LK, Khare AK, et al. Varicella masquerading as pemphigus vulgaris. Indian J Paediatr Dermatol 2018; 19: 176-177.

25. Sinha $P, B$ hattacharjee $S$, Chatterjee M. Varicella bullosa in an adult. Med J Armed Forces India 2017; 73: 311-313.

26. Singh A, Mandal A, Seth R, Sheriff A. Recurrent varicella complicated with staphylococcal scalded skin syndrome in an immunocompromised child. Indian J Child Health 2016; 3: 359-361.

27. Wong KJ, Osowicki J, Seaby E, et al. Bullous Herpes Zoster. J Pediatr 2014; 164: 667.

28. Kurban M, Saleh Z, El Shareef M, et al. Bullous chickenpox: an unusual clinical variant of varicella. Int J Dermatol 2008; 47: 933-935.

29. Sulik A, Szkoda MT, Oldak E. Bullous varicella in a 5-month-old infant. Clin Exp Dermatol 2008; 33: 102-103.

30. Papadopoulos AJ, Janniger CK, Schwartz RA. Chickenpox Guidelines. Medscape; updated: Jun 04, 2018. https://emedicine.medscape.com/article/1131785-guidelines.

31. Committee on Infectious Diseases, American Academy of Pediatrics. Recommended childhood and adolescent immunization schedule - United States, 2014. Pediatrics 2014; 133: 357-363. 